\title{
Advantages and Limitations of Ribosomal RNA PCR and DNA Sequenc- ing for Identification of Bacteria in Cardiac Valves of Danish Patients
}

\author{
Michael Kemp* ${ }^{* 1,2}$, Jette Bangsborg ${ }^{3}$, Anne Kjerulf ${ }^{3}$, Thomas Andersen Schmidt ${ }^{4}$, John \\ Christensen $^{5}$, Akhmadjon Irmukhamedov ${ }^{6}$, Niels Eske Bruun ${ }^{6}$, Rimtas Dargis ${ }^{1,7}$, Keld \\ Andresen $^{1}$ and Jens Jørgen Christensen ${ }^{1,7}$
}

\author{
${ }^{I}$ Microbiological Surveillance \& Research, Statens Serum Institut, Copenhagen, Denmark \\ ${ }^{2}$ Department of Clinical Microbiology, Odense University Hospital, Odense, Denmark \\ ${ }^{3}$ Department of Clinical Microbiology, Herlev University Hospital, Copenhagen, Denmark \\ ${ }^{4}$ The Emergency Department, Holbaek University Hospital, Holbaek, Denmark \\ ${ }^{5}$ Department of Cardiothoracic Surgery, Gentofte University Hospital, Copenhagen, Denmark \\ ${ }^{6}$ Department of Cardiology, Gentofte University Hospital, Copenhagen, Denmark \\ ${ }^{7}$ Department of Clinical Microbiology, Slagelse Hospital, Slagelse, Denmark
}

\begin{abstract}
Studies on the value of culture-independent molecular identification of bacteria in cardiac valves are mostly restricted to comparing agreement of identification to what is obtained by culture to the number of identified bacteria in culture-negative cases. However, evaluation of the usefulness of direct molecular identification should also address weaknesses, their relevance in the given setting, and possible improvements.

In this study cardiac valves from 56 Danish patients referred for surgery for infective endocarditis were analysed by microscopy and culture as well as by PCR targeting part of the bacterial $16 \mathrm{~S}$ rRNA gene followed by DNA sequencing of the PCR product. PCR and DNA sequencing identified significant bacteria in 49 samples from 43 patients, including five out of 13 culture-negative cases. No rare, exotic, or intracellular bacteria were identified. There was a general agreement between bacterial identity obtained by ribosomal PCR and DNA sequencing from the valves and bacterial isolates from blood culture. However, DNA sequencing of the 16S rRNA gene did not discriminate well among non-haemolytic streptococci, especially within the Streptococcus mitis group.

Ribosomal PCR with subsequent DNA sequencing is an efficient and reliable method of identifying the cause of IE, but exact species identification of some of the most common causes, i.e. non-haemolytic streptococci, may be improved with other molecular methods.
\end{abstract}

Keywords: 16S rRNA gene, BLAST, culture independent identification, NCBI database, Streptococcus mitis group, viridans streptococci.

\section{INTRODUCTION}

Infective endocarditis (IE) is a serious condition with a high mortality. Exact identification of the infecting agent is essential for specific and adequate antibiotic therapy. Staphylococcus aureus, non-haemolytic streptococci, Enterococcus faecalis, and haemolytic streptococci are the most common causes of IE found in Denmark [1].

Cardiac surgery may be necessary when the infection has led to severe tissue destruction. Because patients undergoing

\footnotetext{
*Address correspondence to this author at the Dept. of Clinical Microbiology, Odense University Hospital, J.B. Winsløwsvej 21,2, 5000 Odense, DENMARK; Tel: (+45) 6541 3161, Fax: (+45) 6541 4785;

E-mail: michael.kemp@OUH.regionsyddanmark.dk
}

surgery have almost always received antibiotic treatment prior to operation, bacterial culture from removed valves is mostly negative. PCR using universal bacterial primers offers a unique possibility for detecting bacterial DNA in tissue despite a negative culture result. The identity of the infecting bacteria can be established by comparing the DNA sequence of the PCR product to databases of DNA sequences from known species. In addition to establishing the cause of infection after antibiotic treatment, the method allows detection of non-cultivable bacteria such as Coxiella burnetii, Tropheryma whipplei, and Bartonella quintana. In some populations these species are relative frequent causes of IE [2-4], but their frequency in IE in Denmark has not been established. 
The present prospective study was designed to establish the value of PCR and DNA sequencing as a routine method for identifying the aetiology of culture-negative IE in a Danish population and to evaluate the spectrum of infecting bacteria in this population. The accuracy in bacterial identification was particularly addressed. Cardiac valve material from patients who did not suffer from IE was analysed in order to ascertain possible false positive results. Results from PCR and DNA sequence analyses on valves from patients with IE were compared to microscopy and culture. The reliability of species identification by PCR/DNA sequencing of the removed valves was judged by comparing to results from previously obtained blood cultures, if available.

\section{MATERIALS AND METHODS}

\section{Patients}

Patients were referred for cardiac surgery at the cardiothoracic centre at Gentofte University Hospital from other hospitals in the region. Cardiac valve material was obtained from operation for valve replacement or other necessary valve surgery from two groups of patients: one group of patients undergoing surgery on non-infective indications, and another group with IE.

\section{Non-IE Patients (Control Group)}

Tissue samples from 14 mitral and 20 aortic native valves, one tricuspidal, and one biological valve implant from patients who needed valve surgery for non-infective diseases were analyzed. The 36 tissue samples were from 24 men and nine women.

\section{Patients with IE}

Seventy tissue samples from 56 patients (45 men and 11 women) were examined. Thirty two of these were from native aortic valves, 32 were from native mitral valves, one was from native tricuspidal valve, and five were from biological valve implants. From one patient samples were received both from the primary operation and after reoperation one month later, when relapse was suspected. These episodes were treated as two separate patients. One of the patients had IE due to Candida albicans, confirmed by repeated blood cultures. Because the focus of the present study was bacterial IE, the case was included as culture-negative.

At the time of surgery all patients except three fulfilled the revised Duke criteria for IE [5]. One of the three cases was diagnosed with IE during cardiac surgery and DNA from Streptococcus pneumoniae was subsequently demonstrated by analysis of the excised valve.

\section{Microbiological Examinations}

Primary blood cultures were performed and isolated bacteria were identified by local clinical microbiological laboratories according to their individual standards before the patients were referred to the cardiac surgery centre.

The excised valve samples were sent to the Department of Clinical Microbiology, Herlev Hospital and divided in two parts. One part underwent standard microbiological examination including microscopy of Gram-stained smear and culture using the standard aerobic and anaerobic conditions of the laboratory. At microscopy the number of leucocytes (semiquantitatively noted as $0,+,++,+++)$ and the number $(0,+,++,+++)$ and microscopic appearance of visible bacteria were noted. The other part of the excised valves were immersed in DNA grade water and examined by PCR for part of the 16S rRNA gene and DNA sequencing at Statens Serum Institut.

\section{PCR and DNA Sequencing}

The samples included in this study were handled consecutively as a routine procedure together with the processing of other samples submitted for molecular biological examination [6]. DNA was extracted using the QIAamp DNA Mini Kit (Qiagen, Hilden, Germany) according to the manufacturer's recommendations. The primers used for PCR amplification of the 16S rRNA gene (526 bp amplicon) were BSF-8 (5' - AGAGTTTGATCCTGGCTCAG - 3') and BSR-534 (5'- ATTACCGCGGCTGCTGGC - 3'). The Quantitect SYBR Green kit (Qiagen) was used for real-time PCR (50 $\mu \mathrm{l}$ total volume) containing $1 \times$ PCR buffer and $0,2 \mu \mathrm{M}$ of each primer. One and five $\mu 1$ samples were tested in PCR. The amplification profile was $95^{\circ} \mathrm{C}$ for $15 \mathrm{~min}$, followed by 40 cycles at $94^{\circ} \mathrm{C}$ for $30 \mathrm{~s}, 55^{\circ} \mathrm{C}$ for $30 \mathrm{~s}$, and $72^{\circ} \mathrm{C}$ for 30 s. Positive PCR samples were spin column purified using Microcon YM-100 filter units (Millipore, Billerica, MA, USA). Both DNA strands of the amplicons were sequenced on an ABI PRISM 3100 Avant Genetic Analyzer (Applied Biosystems, Foster City, CA, USA) using BSF-8 and BSR-534 as sequencing primers and the BigDye v. 3.1 sequencing kit (Applied Biosystems). Sequencing data were edited using the SeqScape Software (Applied Biosystems) and the DNA sequences were then compared using the BLAST search engine to deposited sequences in the NCBI database, taking into consideration $\%$ / number of identities, Max scores and E-values for the best and the next best taxon matches.

DNA sequences that resulted in low discrimination between species were further analysed using the Ribosomal Database Project (http://rdp.cme.msu.edu) using default setting except for including cultured strains only and EzBioCLoud (www.ezbiocloud.net).

\section{RESULTS}

\section{Examination of Valves in Patients with Non-infective Valve Disease}

Microscopy of the 36 valve tissue samples from the patients without IE showed varying numbers of leucocytes, but no bacteria were visible in any sample. All samples were negative by culture, except for one, from which one colony of Enterococcus faecalis was cultured. Based on careful examination of clinical and laboratory parameters the culture result was judged as due to contamination. DNA from Propionibacterium acnes was identified from seven of the samples.

\section{Valves from Patients with IE}

Forty three of the 56 patients with IE had a positive culture result from either blood or valve material, or both (Table 1). The bacterial species identified by culture were mostly typical causes of IE. One case of IE due to Escherichia coli and three cases caused by haemolytic streptococci group B (Streptococcus agalactiae) were noted. 
Table 1. Number of Patients with Positive Culture Results from Blood, Valve Tissue, or Both, and with Negative Culture Results Within the Groups of Patients with a Positive or Negative PCR Result, Respectively

\begin{tabular}{|c|c|c|c|c|c|}
\hline & Culture +, Blood & Culture +, Tissue & Culture +, Both & Culture -, Both & Total \\
\hline \hline PCR+ & 30 & 1 & 6 & 5 & 42 \\
\hline PCR- & 6 & 0 & 0 & 6 & 13 \\
\hline Total & 36 & 1 & 6 & 56 \\
\hline
\end{tabular}

There was no relation between the number of leucocytes and the detection of bacterial DNA in the valves. In tissue samples with estimated $0,+,++$, and +++ leucocytes the number with/without identification of significant bacteria from PCR were 9/3, 17/10, 15/4, and 8/2, respectively.

Bacteria were visible by microscopy in 22 of 67 examined valves. Significant bacteria were cultured from 8 and identified by PCR and DNA sequencing in 20 of the valves with visible bacteria. The microscopic appearances of the bacteria were in agreement with species identification by DNA sequencing. Bacteria were identified by DNA sequencing in 29 out of 46 samples without visible bacteria.

\section{Species Identification by DNA Sequencing and BLAST Search}

Bacterial identification was obtained for 42 patients by PCR and DNA sequencing, including five out of 13 patients with negative culture results (Table 1). The bacteria identified in these five cases included two $S$. pneumoniae, one $S$. anginosus, and one $S$. mutans. In one culture-negative case BLAST analysis resulted in either $S$. sanguinis or $S$. mitis.

The species determined by DNA sequencing and BLAST search in the NCBI database are shown in Table 2. It appears that the bacterial species identified in this material were all cultivable bacteria. Most bacteria were identified at the species level with high accuracy by PCR for 16S rRNA of excised valve material with subsequent DNA sequencing of the PCR product. Differentiation between species among nonhaemolytic streptococci was generally difficult (see below). Twenty-one patients (34\% of all patients or $40 \%$ of patients for whom a bacterial diagnosis was established) were identified by DNA sequencing as being infected by nonhaemolytic streptococci or S. pneumoniae.

\section{Inconclusive Species Identifications}

In order to establish if there were species of bacteria for which PCR and DNA sequencing did not perform satisfactory, the material was analyzed for identifications with acceptable length of the obtained sequence (arbitrary set to more than $300 \mathrm{bp}$ ) where the difference in maximum score between best and second best taxon matches was less than 20. In 12 patients, i.e. $29 \%$ of patients with a bacterial diagnosis established by DNA sequencing, discrimination between species was problematic. As seen in Table 3, no problems were encountered at the genus level, but exact species identification was in particular difficult among nonhaemolytic streptococci of the mitis group, involving $S$. mitis itself as a possible agent in 10 . Of these 10 cases, three had negative culture results from valves and blood. Mostly, the curated databases Ribosomal Database Project and ElBioCloud confirmed the identifications obtained from the noncurated NCBI database.

\section{DISCUSSION}

In each individual case of IE the choice of antibiotic treatment depends on knowledge of the etiological agent, as does the prognosis [1]. Culture of bacteria, especially from blood, is a cornerstone in the diagnosis of IE, both providing a major diagnostic criterion and establishing the identity and antibiotic susceptibility of the aetiological agent. When cultures from blood and excised valves are negative, a final bacterial diagnosis may be established by cultureindependent techniques, and positive identification by molecular techniques has been suggested as a new diagnostic Duke criterion [7,8]. PCR of part of the 16S rRNA gene with DNA sequencing of the PCR product appears as an attractive method for identifying bacteria causing IE of unknown aetiology, and in the present study it provided bacterial identification in five out of 13 culture-negative cases.

In the present study DNA from $P$. acnes was detected in seven out of 37 samples from patients without IE and in one sample from a patient with IE. Although Propionibacterium species may cause IE, especially in prosthetic valves $[9,10]$, the present findings may be a result of contamination. In the present study no negative control material was forwarded to the laboratory in parallel with the samples. The findings emphasize the importance of critical interpretation of results obtained by molecular technology and of optimizing procedures to avoid contamination from handling and transportation of samples. Still, the possibility that DNA from P. acnes was indeed present in the valves remains. Future studies have to clarify the possible role of $P$. acnes in cardiac valve disease.

The patients included in the present study represented a selected group of patients suffering from IE since only patients referred for surgery could be included. Baseline characteristics and prognosis differs between groups of patients with IE receiving surgery and patients treated with antibiotics alone [1].

Leucocyte infiltration as estimated by standard microscopy was not an indicator of presence of bacterial DNA in heart valve material in the present study. Therefore decisions on whether to perform PCR in individual cases should not rely on the result of the presence of leucocytes in the valve material. Neither should lack of visible bacteria lead to refraining from pursuing PCR and DNA sequencing, because bacteria were demonstrated and identified in approximately two thirds of samples without visible bacteria.

The species identified in the present study were largely well known causes of IE, mainly non-haemolytic streptococ- 
Table 2. Bacteria Identified by DNA Sequencing of PCR Products from Partial Amplification of the 16S rRNA Gene from Cardiac Valves and Culture Results from the Patients

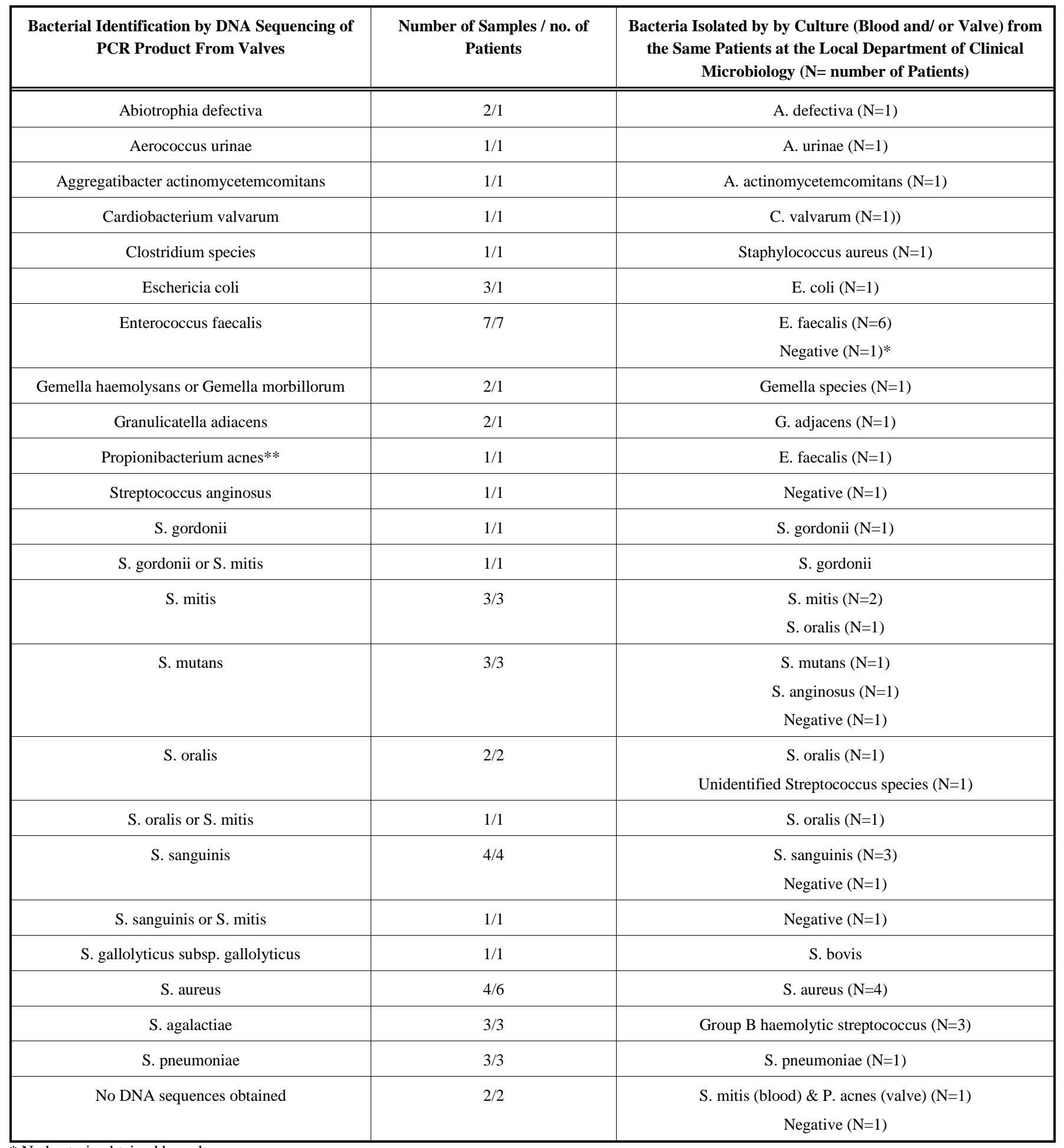

* No bacteria obtained by culture.

** P. acnes was identified from one of two samples from the mitral valve. E. faecalis was detected in the other sample.

ci, enterococci, and Staphylococcus aureus. The three cases of IE due to $S$. agalactiae were unexpected as this has been considered a rare cause of IE [11]. In all cases, group B haemolytic streptococci had been cultured from blood before cardiac surgery. The incidence of bacteraemia caused by group B streptococci has been increasing in Denmark as well as in USA in recent years [12,13] and the present finding may represent a true increase in IE caused by this bacterium.

At present we have no explanation for the finding of DNA from a Clostridium species on valve material in one patient from whom $S$. aureus had been cultured from the 
Table 3. Bacteria identified by DNA sequencing of PCR products obtained from cardiac valves. Best and second best match of BLAST search in the NCBI database and the difference in max scores are shown for bacterial identifications with differences in score value less than 20. Best matching species in the Ribosomal Database Project and EzBioCloud are shown for the same amplicon DNA sequences.

\begin{tabular}{|c|c|c|c|c|c|}
\hline $\begin{array}{l}\text { NCBI Database } \\
\text { Best Match }\end{array}$ & $\begin{array}{c}\text { NCB Database } \\
\text { Second Best Match }\end{array}$ & $\begin{array}{l}\text { Max Score Dif- } \\
\text { ference }\end{array}$ & $\begin{array}{c}\text { Ribosomal Data- } \\
\text { base Project }\end{array}$ & EzBioCloud & $\begin{array}{c}\text { Culture } \\
\text { Result }\end{array}$ \\
\hline Streptococcus pneumoniae & S. mitis & 3 & S. pneumoniae & S. pneumoniae & S. pneumoniae \\
\hline S. mitis or $S$. gordonii & $-*$ & 0 & S. gordonii & S. gordonii & S. gordonii \\
\hline S. mitis & S. pneumoniae & 5 & S. mitis & S. mitis & S. mitis \\
\hline S. sanguinis & S. oralis & 7 & S. sanguinis & S. sanguinis & S. sanguinis \\
\hline S. pneumoniae & S. mitis & 9 & S. pneumoniae & S. pneumoniae & Negative \\
\hline S. pneumoniae & S. mitis & 16 & S. pneumoniae & S. pneumoniae & Negative \\
\hline S. oralis or S. mitis & - & 0 & S. oralis & S. orisratti & S. oralis \\
\hline S. mitis or S. sanguinis & - & 0 & S. mitis or S. oralis & S. pseudopneumoniae & S. oralis \\
\hline S. gordonii & S. mitis & 8 & S. gordonii & S. gordonii & S. gordonii \\
\hline S. gordonii & S. mitis & 15 & S. gordonii & S. gordonii & S. gordonii \\
\hline S. sanguinis & $\begin{array}{c}\text { S. mitis or } S . \text { oralis or } S . \\
\text { pneumoniae }\end{array}$ & 16 & $\begin{array}{l}\text { S. oralis or } S \text {. mitis } \\
\quad \text { or } S . \text { sanguinis }\end{array}$ & S. oralis & Negative \\
\hline $\begin{array}{l}\text { Gemella haemolysans or } G \text {. } \\
\text { morbillorum }\end{array}$ & - & 0 & G. mobilliorum & G. mobilliorum & $\begin{array}{l}\text { Gemella spe- } \\
\text { cies }\end{array}$ \\
\hline
\end{tabular}

* - Same max score value by more than one species.

blood. Most likely the molecular identification was due to contamination of the sample.

Studies from different parts of the world have focused on the use of PCR and DNA sequencing in IE [14-23]. Results have varied, especially with respect to the number of noncultivable bacteria detected. Using PCR and DNA sequencing of the 16S rRNA gene Podglainjen et al. [24] demonstrated three cases of $B$. quintana and one case of $B$. henselae in six culture-negative infected heart valves. Three of the patients with endocarditis caused by Bartonella species in that study were from Africa. No non-cultivable bacteria were identified in the material presented here. Another Danish study reported two cases of IE caused by T. whipplei [23]. Surprisingly, Q fever endocarditis has been found in Denmark in a patient from Greenland [25]. Despite recognition of $C$. burnetii being prevalent in cattle in Denmark and the presence of low level antibodies in occupationally exposed persons [26], Q fever is very rare in Denmark and no cases of $\mathrm{Q}$ fever endocarditis aquired in Denmark have been reported. A few cases of IE due to $B$. quintana have been found in Denmark (unpublished observation). Thus it seems that the reason for negative culture results in Danish cases of IE is only rarely infections with non-cultivable bacteria. Similar findings have recently been reported from Sweden [27].

As intense antibiotic treatment is most often initiated before surgery takes place, culture of valve material would usually be negative, as in the material presented here. However, bacterial DNA has been reported to persist in heart valves for months or even years after successful treatment of
IE [28,29]. It is important that a past history of well-treated IE does not lead to a false positive interpretation of results obtained by molecular examination of excised valves [30].

One of the cases with negative results from PCR and bacterial culture in the present study had infective endocarditis caused by $C$. albicans. Supplementing PCR for bacterial DNA with a universal fungal PCR will probably further increase the number of patients for whom the cause of IE can be established [19].

In general, comparing obtained partial DNA sequences of the $16 \mathrm{~S}$ rRNA gene to the NCBI database resulted in excellent bacterial identification. However, for S. pneumoniae and viridans streptococci, particularly $S$. mitis, there were serious difficulties in discriminating between species. Although not of significance to treatment, the lack of unambiguous identification is unsatisfactory, especially because in between of $15 \%$ and $44 \%$ of the cases the bacteria causing IE are viridans streptococci [1]. Using the same technique as in the present study, similar difficulties have been found on bacterial strains isolated from the blood of patients with and without IE [31]. Other targets for DNA sequencing than the $16 \mathrm{~S}$ rRNA gene may be valuable in distinguishing between species within the group of non-haemolytic streptococci [32]. The usefulness of such alternative targets in identification of bacteria by universal PCR and DNA sequencing should be investigated in future studies.

\section{CONFLICT OF INTEREST}

The authors confirm that this article content has no conflicts of interest. 


\section{ACKNOWLEDGMENTS}

None declared.

\section{REFERENCES}

[1] Le V, Gill S. Serious complications after infective endocarditis. Dan Med Bull 2010; 57: A4192

[2] Casalta JP, Gouriet F, Richet H, Thuny F, Habib G, Raoult D. Prevalence of Coxiella burnetii and Bartonella species as cases of infective endocarditis in Marseilles (1994-2007). Clin Microbiol Infect 2009; 15 suppl 2: 152-3.

[3] Houpikian P, Raoult D. Blood culture-negative endocarditis in a reference center: etiologic diagnosis of 348 cases. Medicine (Baltimore) 2005; 84: 162-73.

[4] Znazen A, Rolain JM, Hammami N, Kammoun S, Hammami A, Raoult D. High prevalence of Bartonella quintana endocarditis in Sfax, Tunisia. Am J Trop Med Hyg 2005; 72: 503-7.

[5] Li JS, Sexton DJ, Mick N et al. Proposed modifications to the Duke criteria for the diagnosis of infective endocarditis. Clin Infect Dis 2000; 30: 633-8.

[6] Grarup C, Gleesen AS, Dargis R, Andresen K, Christensen JJ, Kemp M. Infections with beta-haemolytic streptococci: detection by a universal PCR for bacterial DNA and DNA sequencing. Scand J Infect Dis 2008; 40: 547-50.

[7] Lisby G, Gutschik E, Durack, DT. Molecular methods for diagnosis of infective endocarditis. Infect Dis Clin North Am 2002; 16 : 393-412.

[8] Millar B, Moore J, Mallon P et al. Molecular diagnosis of infective endocarditis--a new Duke's criterion. Scand J Infect Dis 2001; 33: 673-80.

[9] Lalani T, Person AK, Hedayati SS et al. Propionibacterium endocarditis: a case series from the International collaboration on endocarditis merged database and prospective cohort study. Scand J Infect Dis 2007; 39: 840-8.

[10] Sohail MR, Gray AL, Baddour LM, Tleyjeh IM, Virk A. Infective endocarditis due to Propionibacterium species. Clin Microbiol Infect 2009; 15: 387-94.

[11] Georgieva IR, Lopez GMV, Ruiz-Morales J, et al. Streptococcus agalactiae left-sided infective endocarditis. Analysis of 27 cases from a multicentric cohort. J Infect 2010; 61: 54-9.

[12] Skoff TH, Farley MM, Petit S et al. Increasing burden of invasive group B streptococcal disease in nonpregnant adults, 1990-2007. Clin Infect Dis 2009; 49: 85-92.

[13] Lambertsen L, Ekelund K, Skovsted IC, Liboriussen A, Slotved HC. Characterisation of invasive group B streptococci from adults in Denmark 1999 to 2004. Eur J Clin Microbiol Infect Dis 2010; 29: 1071-7.

[14] Bosshard PP, Kronenberg A, Zbinden R, Ruef C, Bottger EC, Altwegg M. Etiologic diagnosis of infective endocarditis by broadrange polymerase chain reaction: a 3-year experience. Clin Infect Dis 2003; 37: 167-72.

[15] Breitkopf C, Hammel D, Scheld HH, Peters G, Becker K. Impact of a molecular approach to improve the microbiological diagnosis of infective heart valve endocarditis. Circulation 2005; 111: 1415-21.

[16] Gauduchon V, Chalabreysse L, Etienne J, et al. Molecular diagnosis of infective endocarditis by PCR amplification and direct se- quencing of DNA from valve tissue. J Clin Microbiol 2003; 41: 763-6.

Goldenberger D, Kunzli A, Vogt P, Zbinden R, Altwegg M. Molecular diagnosis of bacterial endocarditis by broad-range PCR amplification and direct sequencing. J Clin Microbiol 1997; 35: 27339.

[18] Greub G, Lepidi H, Rovery C et al. Diagnosis of infectious endocarditis in patients undergoing valve surgery. Am J Med 2005; 118 : 230-8.

[19] Grijalva M, Horvath R, Dendis M, Erny J, Benedik J. Molecular diagnosis of culture negative infective endocarditis: clinical validation in a group of surgically treated patients. Heart 2003; 89: 263-8.

[20] Kotilainen P, Heiro M, Jalava J, et al. Aetiological diagnosis of infective endocarditis by direct amplification of rRNA genes from surgically removed valve tissue. An 11-year experience in a Finnish teaching hospital. Ann Med 2006; 38: 263-23.

[21] Lang S, Watkin RW, Lambert PA, Bonser RS, Littler WA, Elliott TS. Evaluation of PCR in the molecular diagnosis of endocarditis. J Infect 2004; 48: 269-75.

[22] Marin M, Munoz P, Sanchez M et al. Molecular diagnosis of infective endocarditis by real-time broad-range polymerase chain reaction (PCR) and sequencing directly from heart valve tissue. Medicine (Baltimore) 2007; 86: 195-202.

[23] Voldstedlund M, Pedersen LN, Baandrup U, Klaaborg KE, Fuursted K. Broad-range PCR and sequencing in routine diagnosis of infective endocarditis. APMIS 2008; 116: 190-8.

[24] Podglajen I, Bellery F, Poyart C et al. Comparative molecular and microbiologic diagnosis of bacterial endocarditis. Emerg Infect Dis 2003; 9: 1543-7.

[25] Koch A, Svendsen CB, Christensen JJ, et al. Q fever in Greenland. Emerg Infect Dis 2010; 16: 511-3.

[26] Bosnjak E, Hvass AM, Villumsen S, Nielsen H. Emerging evidence for $\mathrm{Q}$ fever in humans in Denmark: role of contact with dairy cattle. Clin Microbiol Infect 2009; 16: 1285-8.

[27] Vondracek M, Sartipy U, Aufwerber E, Julander I, Lindblom D, Westling K. 16S rDNA sequencing of valve tissue improves microbiological diagnosis in surgically treated patients with infective endocarditis. J Infect 2011; 62: 472-8.

[28] Branger S, Casalta JP, Habib G, Collard F, Raoult D. Streptococcus pneumoniae endocarditis: persistence of DNA on heart valve material 7 years after infectious episode. J Clin Microbiol 2003; 41: 4435-7.

[29] Lang S, Watkin RW, Lambert PA, Littler WA, Elliott TS. Detection of bacterial DNA in cardiac vegetations by PCR after the completion of antimicrobial treatment for endocarditis. Clin Microbiol Infect 2004; 10: 579-81.

[30] Rovery C, Greub G, Lepidi H et al. PCR detection of bacteria on cardiac valves of patients with treated bacterial endocarditis. J Clin Microbiol 2005; 43: 163-7.

[31] Abdul-Redha R, Kemp M, Bangsborg JM, Arpi M, Christensen JJ Identification of Catalase-Negative, Gram-Positive Cocci from Blood Cultures by Partial 16S rRNA Gene Analysis and by Vitek 2 Examination. Open Microbiol J 2010; 4: 116-22.

[32] Nielsen XC, Justesen US, Dargis R, Kemp M, Christensen JJ Identification of clinically relevant nonhemolytic Streptococci on the basis of sequence analysis of $16 \mathrm{~S}-23 \mathrm{~S}$ intergenic spacer region and partial gdh gene. J Clin Microbiol 2009; 47: 932-9.

(C) Kemp et al.; Licensee Bentham Open.

This is an open access article licensed under the terms of the Creative Commons Attribution Non-Commercial License (http://creativecommons.org/licenses/ by-nc/3.0/) which permits unrestricted, non-commercial use, distribution and reproduction in any medium, provided the work is properly cited. 